\title{
Method for Residues Analysis of Isoxaflutole and Its Metabolites in Maize
}

\author{
Mao Jia ${ }^{1}$, Feng Yizhi ${ }^{2}$,i Xiaoxue ${ }^{2}$, Han Jifeng ${ }^{2}$, Pan Jinju ${ }^{2}$, Liang Lin $^{2}$, Liu Wei ${ }^{2}$, Zuo Bojun ${ }^{2, *}$ \\ ${ }^{1}$ Institute of Agriculture Environment and Resource, Yunnan Academy of Agricultural Sciences, Kunming, China \\ ${ }^{2}$ Key Laboratory for Chemical Pesticide of Shandong Province, Shandong Academy of Pesticide Sciences, Jinan, China
}

Email address:

1984fengyizhi@163.com (Feng Yizhi),1121378261@qq.com (Zuo Bojun)

${ }^{*}$ Corresponding author

\section{To cite this article:}

Mao Jia, Feng Yizhi, Qi Xiaoxue, Han Jifeng, Pan Jinju, Liang Lin, Liu Wei, Zuo Bojun. Method for Residues Analysis of Isoxaflutole and Its Metabolites in Maize. Science Journal of Chemistry. Vol. 7, No. 4, 2019, pp. 72-76. doi: 10.11648/j.sjc.20190704.11

Received: September 11, 2019; Accepted: October 7, 2019; Published: October 17, 2019

\begin{abstract}
A rapid and sensitive analytical method for the determination of isoxaflutole and diketonitrile (DKN) residues in maize was established based on QuEChERS (Quick, Easy, Cheap, Effective, Rugged and Safe) and high performance liquid chromatography with tandem mass spectrometry (HPLC-MS/MS). The samples were extracted with acetonitrile and purified with octadecylsilane $\left(\mathrm{C}_{18}\right)$. The mass spectrometer was performed in multi-reaction monitoring mode, and electrospray ionization in negative mode was selected. The isoxaflutole and DKN residues were quantified by the external standard method using the matched standard solution to compensate for matrix effect. The results indicated that the calibration curves of isoxaflutole and DKN were linear in the range of $0.005-0.5 \mathrm{mg} / \mathrm{L}$ with correlation coefficients of more than 0.9922 . When the addition level ranged from 0.01 to $0.1 \mathrm{mg} / \mathrm{kg}$ the average recoveries of isoxaflutole and DKN in maize, green maize and straw were $95 \%-108 \%$, and the relative standard deviation (RSD) ranged from $2 \%$ to $11 \%$. The limit of quantitation (LOQ) were 0.01 $\mathrm{mg} / \mathrm{kg}$ in different matrices. This method has many characteristics, such as simple, rapid and accurate, and can be adapted for the confirmation of isoxaflutole and DKN residues in maize samples.
\end{abstract}

Keywords: Isoxaflutole, Metabolites, Maize, Method, Residues

\section{Introduction}

Isoxaflutole (Figure 1) is a selective pre-emergent herbicide, which is mainly used in the field of corn and sugarcaneto control various annual broadleaf weeds and some gramineous weeds. Isoxaflutole was rapidly hydrolyzed to DKN after sprayed into soil. The mode of action of isoxaflutole is the inhibition of the enzyme 4-hydroxyphenylpyruvate dioxygenase (HPPD), thereby inhibiting pigment formation, and causing bleaching of the developing tissues of the weeds [1]. Currently, the dietary risk assessment of isoxaflutole was defined by CAC, the United States, Japan and European Union [2-5] as isoxaflutole and DKN, and were measured by isoxaflutole. There is few reports on the methods for analysis of isoxaflutole and its metabolites residues, mainly involving water, soil and forage plant [6-8]. Yang Changzhi et al. [9] established a HPLC-MS/MS method for simultaneous determination of isoxaflutole and DKN in maize by APCI source combined with QuEChERS, but it did not involve maize straw. Up to now, China has not established the maximum residue limit of isoxaflutole inmaize [10], while CAC, the United States, Japan and European Union all set the maximum residue limits $(0.02 \mathrm{mg} / \mathrm{kg})$ for maize. At present, the registration of isoxaflutole on maize is being carried out in our country, so it is urgent to establish the method of residue analysis on maize and maize straw. In this study, the residue analysis method of isoxaflutole and $\mathrm{DKN}$, in maize and maizestraw was establishedby HPLC-MS/MS.
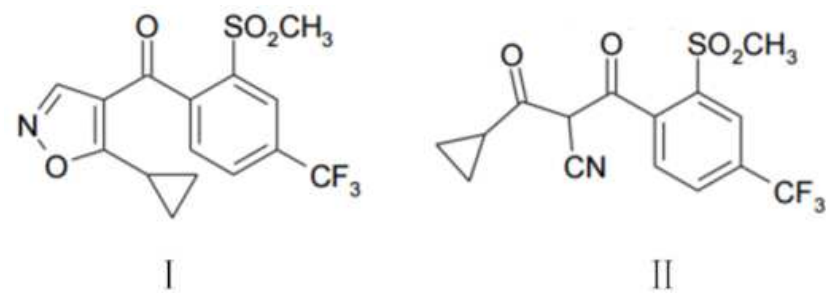

Figure 1. Chemical structures of Isoxaflutole (I) and DKN (II). 


\section{Materials and Methods}

\subsection{Materials}

Isoxaflutole (CAS: 141112-29-0, 99.6\%purity); DKN (CAS: 143701- 75-1, 99.5\% purity) were obtained from Dr. Ehrenstorfer GmbH; HPLC-MS/MS (LCMS-8040) was from shimadzu; jiuyang food processor (JYL-C020E) was from jiuyang Co., Ltd.; electronic balance (JA21002) was from shanghai precision scientific instruments Co., Ltd.; tabletop centrifuge (sorvall ST16) was from thermofisher; acetonitrile (chromatographic grade) was purchased from fisher scientific; sodium chloride (analytical grade), ammonium acetate (chromatographic grade) were purchased from china pharmaceutical group chemical reagents Co., Ltd.; C18 (40 60 $\mu \mathrm{m})$ was obtained from agela technologies.

\subsection{Methods}

\subsubsection{Chromatographic Determination Conditions}

The separation was performed on Shim-pack XR-ODS II (75 $\mathrm{mm} \times 2.0 \mathrm{~mm}$ i.d., $2.2 \mu \mathrm{m}$ particle size). The mobile phase consisting of $5 \mathrm{mmol}$ ammonium acetate aqueous solution (solvent A) and acetonitrile (solvent B) was pumped at a flow rate of $0.3 \mathrm{mLmin}^{-1}$. The gradient elution program was as follows: 0-1 $\mathrm{min}, 20-80 \% \mathrm{~B}$; 1-2min, $80-20 \% \mathrm{~B}$; 2-2.5 min, $20 \% \mathrm{~B}$ retention; and column equilibration. The column oven temperature was maintained at room temperature, and the temperature in the sample manager was set at $15^{\circ} \mathrm{C}$. The sample volume injected was maintained at $2 \mu \mathrm{L}$. The nebulizer gas was nitrogen, and the collision was argon. MS/MS detection was performed in negative mode. Typical conditions were as follows: capillary voltage, $3.5 \mathrm{kV}$; heating block temperature, $400^{\circ} \mathrm{C}$; and drying gas temperature, $250^{\circ} \mathrm{C}$; drying gas flow rate, $15 \mathrm{~L} / \mathrm{min}$; atomized gas flow rate, $3 \mathrm{~L} / \mathrm{min}$. In total, $\mathrm{m} / \mathrm{z} 358$ was selected as the precursor ion; its product quantitative ion and qualitative ion were $\mathrm{m} / \mathrm{z} 79$ and $\mathrm{m} / \mathrm{z} 358$, respectively, when the corresponding collision energy levels were set at 20 and $30 \mathrm{~V}$.

\subsubsection{Pretreatment}

In total $5.0 \mathrm{~g}$ aliquots of homogenized samples were weighed into $50 \mathrm{~mL}$ Teflon tubes, and water $(5 \mathrm{~mL})$ and acetonitrile $(10 \mathrm{~mL})$ were added. The mixtures were vortexed for $5 \mathrm{~min}$, then $4 \mathrm{~g}$ sodium chloride were added. The tubes were capped and immediately vortexed vigorously for $1 \mathrm{~min}$ and then centrifuged for $5 \mathrm{~min}$ at $4000 \mathrm{rpm}$. Then, $1 \mathrm{~mL}$ of the upper layer (acetonitrile) was transferred into a single-usecentrifuge tube and $50 \mathrm{mg} \mathrm{C} 18$ was added. The samples were vortexed for $1 \mathrm{~min}$ and filtered through $0.22 \mu$ mnylon syringe filters for HPLC/MS/MS injection.

\subsubsection{Preparation of Calibration Curve}

Isoxaflutole and DKN standard reserve solution: appropriate isoxaflutole and DKN standard substances were accurately weighed, dissolved with acetonitrile and volumed in $25 \mathrm{~mL}$ brown volumetric flask respectively. Standard reserve solution was obtainedwith mass concentration of $100 \mathrm{mg} / \mathrm{L}$. Accurate removal of $1 \mathrm{~mL}$ to $10 \mathrm{~mL}$ volumetric flasks of isoxaflutole and DKN, and volumetric calibration with acetonitrile to obtain 10 $\mathrm{mg} / \mathrm{L}$ mixed solution. Standard solutions of $0.5,0.1,0.05,0.01$ and $0.005 \mathrm{mg} / \mathrm{L}$ were diluted with acetonitrile, maize blank matrix, green maize blank matrix and straw blank matrix, respectively, and determined under 1.2.1 section of chromatographic conditions. Each mass concentration was repeated three times, and the peak area of each component was plotted according to the mass concentration of standard working solution.

\subsubsection{Recovery}

Maize, green maize and straw were all spiked at three differentlevels of isoxaflutole and DKN $(0.01,0.05,0.1 \mathrm{mg} / \mathrm{kg}$ based on five replicates). Extraction and purification were carried out according to 1.2.2 section, and detection was carried out according to 1.2.1 section chromatographic conditions. Recovery rate and relative standard deviation were determined.

\section{Results and Analysis}

\subsection{Mass Spectrometric Conditions}

The full-scan (m/z 50 500) of $10 \mathrm{mg} / \mathrm{L}$ isoxaflutole and DKN standard solution was carried outunder electrospray ionization ESI (+ / -). The experimental results show that the negative ion scanning mode can make isoxaflutole and DKN have better ionization effect. Because of the similar structure and the same molecular weight, isoxaflutole and DKN have the same characteristic ion peak [M-1] (m/z 358.00), the quantitative ion pair $\mathrm{m} / \mathrm{z} 358.00 / 79.00$ and the qualitative ion pair $\mathrm{m} / \mathrm{z}$ $358.00 / 358.00$ (Figure 2). In this experiment, the retention time of isoxaflutole and DKN was used to characterize them. The retention time of isoxaflutole and DKN was $2.05 \mathrm{~min}$ and 1.42 min respectively.

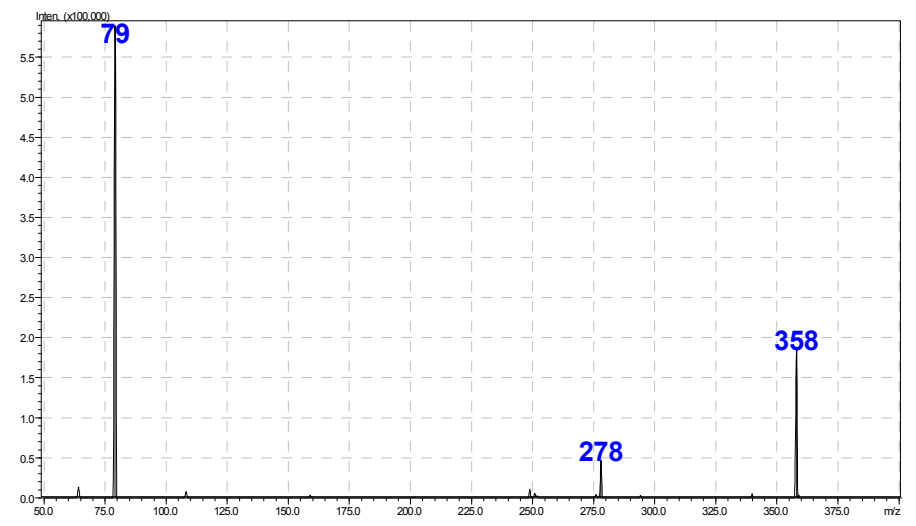




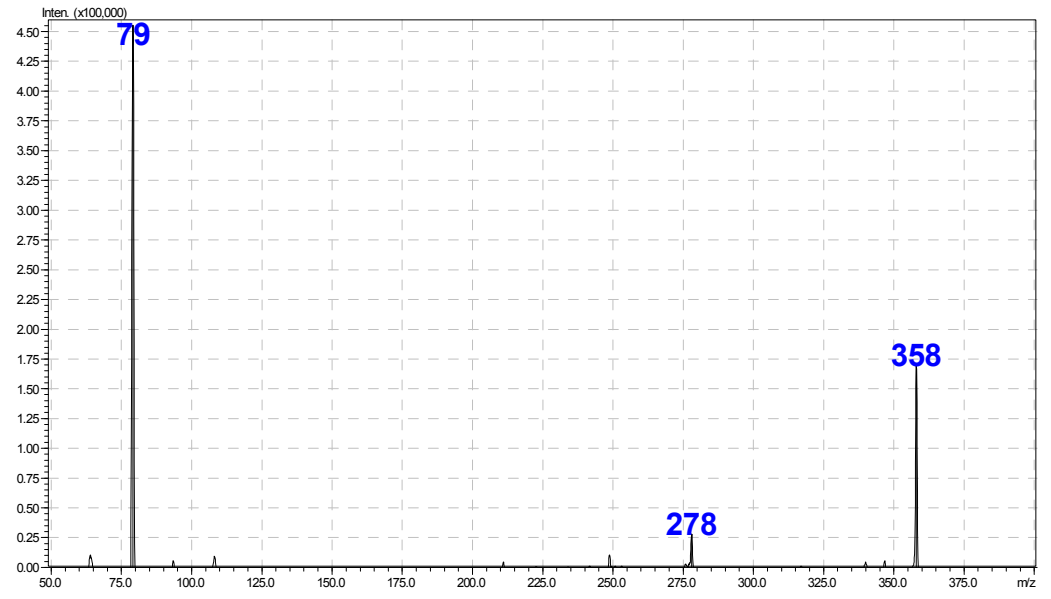

Figure 2. Isoxaflutole and DKN secondary mass spectrogram.

\subsection{Linear Range and Matrix Effect}

The results showed that in the range of $0.005-0.5 \mathrm{mg} / \mathrm{L}$, the quantitative ion peak area of isoxaflutole and DKN in acetonitrile, maize blank matrix, green maize blank matrix and straw blank matrix had a good linear relationship with the sample concentration (Table 1), and the correlation coefficient (r) was higher than 0.9922 . In this experiment, the matrix effect was evaluated by $\mathrm{K}$ value with reference to LIU et al [11-16], i.e. the ratio of matrix standard curve slope to solvent standard curve slope (K).

The matrix effect could be ignored if the $\mathrm{K}$ value was in the range of $0.9 \sim 1.1: \mathrm{K}$ values $<0.9$ indicate matrix suppression effects, and $\mathrm{K}$ values $>1.1$ indicate matrix enhancement effect. Table 2 shows that isoxaflutole and DKN have different matrix effects in maize and other substrates, in which isoxaflutole matrix weakens significantly, while DKN matrix enhances significantly. If the standard solution of non- matrix-matched was used to calculate, the recovery of isoxaflutole in maize substrates was low, while the recovery of DKN was high. In this study, calibration was performed with external matrix-matched standards to eliminate the matrix effect.

Table 1. Linear equation, correlation coefficient, slope ratio and quantitative limits ofisoxaflutole and DKN.

\begin{tabular}{llllll}
\hline Compound & Matrix & Linear equation & Correlation correlation $\mathbf{r}$ & Slope ratio K & LOQ/(mg/kg) \\
\hline \multirow{4}{*}{ isoxaflutole } & acetonitrile & $\mathrm{y}=569068 \mathrm{x}-92$ & 0.9999 & - & 0.01 \\
& maize & $\mathrm{y}=373304 \mathrm{x}-738$ & 0.9999 & 0.66 & 0.01 \\
& green maize & $\mathrm{y}=375267 \mathrm{x}-689$ & 0.9999 & 0.66 & 0.01 \\
& straw & $\mathrm{y}=256418 \mathrm{x}-133$ & 0.9999 & 0.45 & 0.01 \\
& acetonitrile & $\mathrm{y}=951473 \mathrm{x}+33139$ & 0.9922 & - & 0.01 \\
DKN & maize & $\mathrm{y}=1410993 \mathrm{x}+16579$ & 0.9986 & 1.52 & 0.01 \\
& green maize & $\mathrm{y}=1425114 \mathrm{x}+19322$ & 0.9977 & 1.50 & 0.01 \\
& straw & $\mathrm{y}=1413229 \mathrm{x}+5724$ & 0.9997 & 1.49 & 0.01 \\
\hline
\end{tabular}

\subsection{Recovery and Precision}

Three different mass fractions of isoxaflutole and DKN standard solutions were added to the blank samples of maize, green maize and straw, respectively. The results showed that (Table 2): isoxaflutole and DKN were added to maize, green maize and straw with different levels. The recovery was $85 \% \sim 117 \%$, and the relative standard deviation was $2 \% \sim 11 \%$, which met the requirements of pesticide residue analysis standard. Typical spectra are shown in Figure 3.
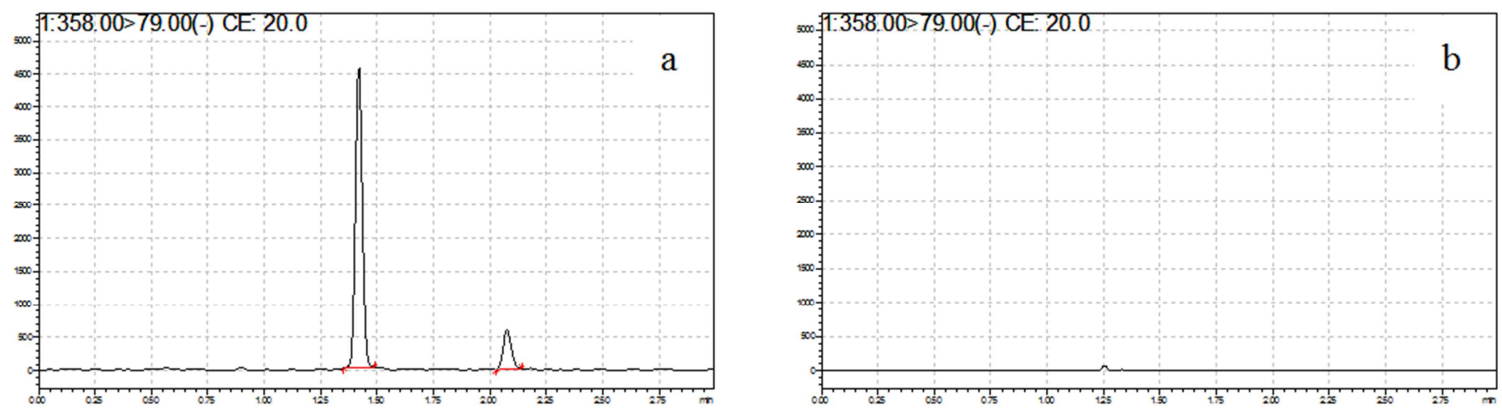

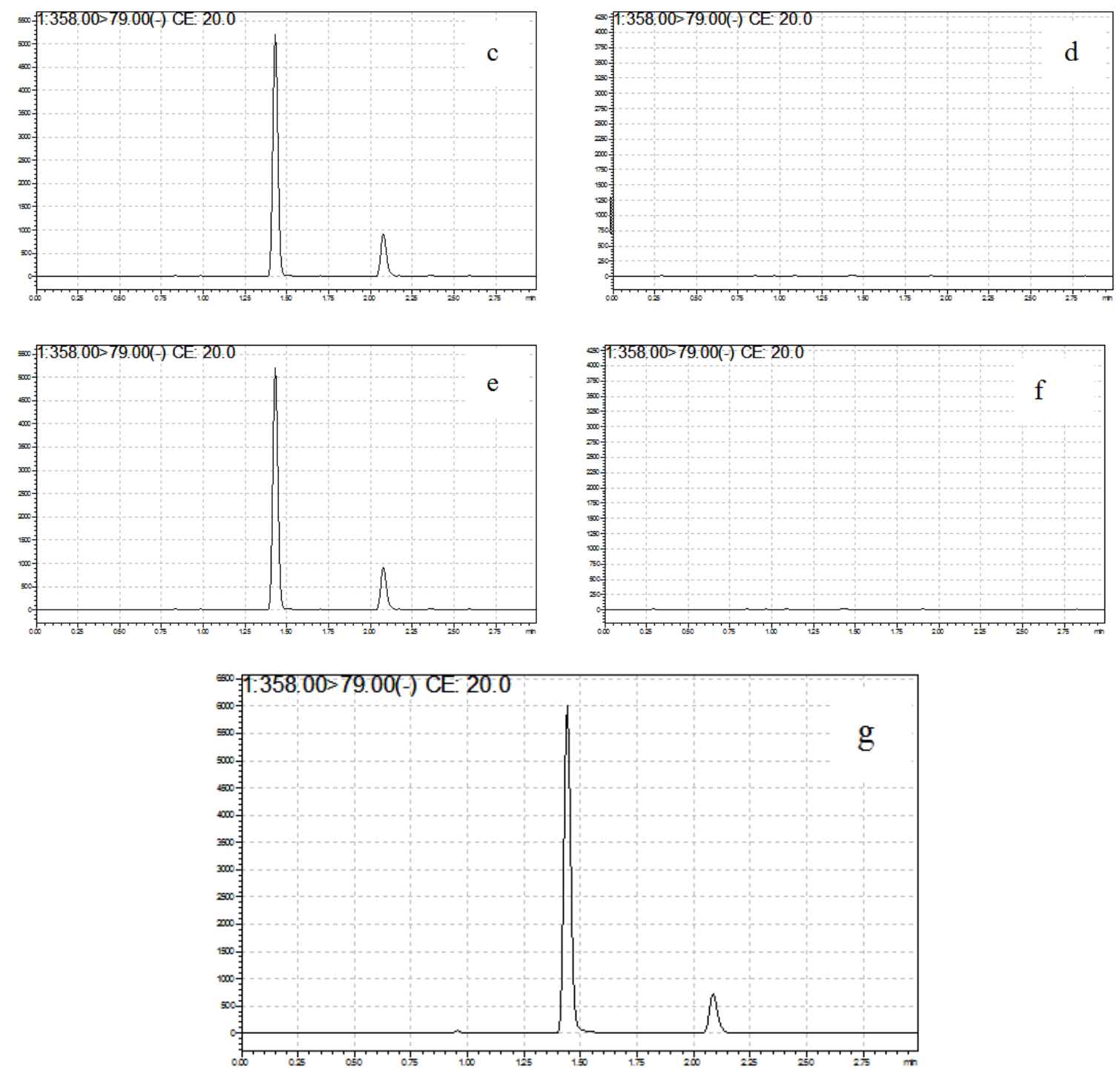

Figure 3. Chromatograms of (a)isoxaflutole and DKN, (b) blank maize sample, (c) maize sample spiked at $0.01 \mathrm{mg} / \mathrm{kg}$, (d) blank green maize sample, (e) green maize sample spiked at $0.01 \mathrm{mg} / \mathrm{kg}$. (f) blank straw sample and (g) straw sample spiked at $0.01 \mathrm{mg} / \mathrm{kg}$.

Table 2. Result of recovery of isoxaflutole and DKN in maize, green maize and straw.

\begin{tabular}{|c|c|c|c|c|c|c|c|c|c|}
\hline \multirow{2}{*}{ Compound } & \multirow{2}{*}{ Matrix } & \multirow{2}{*}{ Spiked level $\left(\mathrm{mg} \cdot \mathrm{kg}^{-1}\right)$} & \multicolumn{5}{|c|}{ Recovery/\% } & \multirow{2}{*}{ Mean Recovery/\% } & \multirow{2}{*}{ RSD $/ \%$} \\
\hline & & & 1 & 2 & 3 & 4 & 5 & & \\
\hline \multirow{9}{*}{ Isoxaflutole } & \multirow{3}{*}{ maize } & 0.01 & 101 & 95 & 89 & 90 & 102 & 95 & 6 \\
\hline & & 0.05 & 88 & 99 & 101 & 98 & 103 & 98 & 6 \\
\hline & & 0.1 & 103 & 103 & 97 & 97 & 104 & 101 & 3 \\
\hline & \multirow{4}{*}{ Green maize } & 0.01 & 95 & 85 & 98 & 100 & 103 & 96 & 7 \\
\hline & & 0.05 & 99 & 103 & 106 & 106 & 98 & 102 & 4 \\
\hline & & 0.1 & 97 & 92 & 92 & 93 & 99 & 95 & 3 \\
\hline & & 0.01 & 86 & 102 & 97 & 115 & 106 & 101 & 11 \\
\hline & \multirow[t]{3}{*}{ straw } & 0.05 & 97 & 101 & 95 & 96 & 103 & 98 & 4 \\
\hline & & 0.1 & 95 & 105 & 103 & 100 & 105 & 102 & 4 \\
\hline \multirow{9}{*}{ DKN } & & 0.01 & 99 & 104 & 100 & 98 & 96 & 99 & 3 \\
\hline & \multirow[t]{3}{*}{ maize } & 0.05 & 95 & 94 & 92 & 95 & 104 & 96 & 5 \\
\hline & & 0.1 & 98 & 96 & 98 & 95 & 99 & 97 & 2 \\
\hline & & 0.01 & 117 & 110 & 103 & 108 & 100 & 108 & 6 \\
\hline & \multirow[t]{3}{*}{ Green maize } & 0.05 & 103 & 104 & 101 & 97 & 105 & 102 & 3 \\
\hline & & 0.1 & 98 & 97 & 101 & 95 & 104 & 99 & 4 \\
\hline & & 0.01 & 92 & 97 & 100 & 108 & 103 & 100 & 6 \\
\hline & \multirow[t]{2}{*}{ straw } & 0.05 & 92 & 103 & 94 & 90 & 94 & 95 & 5 \\
\hline & & 0.1 & 85 & 96 & 98 & 101 & 97 & 95 & 6 \\
\hline
\end{tabular}




\section{Results}

A method was developedfor the determination of isoxaflutole and DKN residues in maize and other substrates by dispersive solid phase extraction coupled with HPLC-MS/MS. The results showed that the LOQ of isoxaflutole and DKN in maize, green maize and straw were $0.01 \mathrm{mg} / \mathrm{kg}$. The recoveries of isoxaflutole and DKN at different levels were $85 \% \sim 117 \%$ and the relative standard deviations were $2 \% \sim 11 \%$.

\section{Conclusion}

In this study, an analytical method for the simultaneous detection of isoxaflutole and DKNin maize and other substrates has been developed based onQuEChERSand HPLC-MS/MS. The sensitivity of the method is improved, and the efficiency of extraction and purification in pretreatment is also increased. It has the characteristics of fast, simple, high efficiency and low cost. It is suitable for rapid determination of isoxaflutole and DKN in large amounts of maize and other substrates.

\section{Acknowledgements}

This work was financially supported by Agricultural Science and Technology Innovation Project of Shandong Academy of Agricultural Sciences (CXGC2018E19).

\section{References}

[1] Pallett K E, Little J P, Sheekey M, et al. The mode of action of isoxaflutoleI. physiologicaleffects, metabolism, and selectivity [J]. Pesticide Biochemistry and Physiology, 1998, 62 (2): $113-124$.

[2] http://www.fao.org/fao-who-codexalimentarius/codex-texts/db s/pestres/pesticide-detail/en/?p_id=268

[3] https://www.ecfr.gov/cgi-bin/retrieveECFR?gp=1\&SID=e8a5 b861d874af20b816afd7f193bbfb\&ty=HTML\&h=L\&mc=true $\& \mathrm{r}=$ SECTION\&n=se40.26.180_1537

[4] http://db.ffcr.or.jp/front/pesticide_detail?id=6700

[5] https://ec.europa.eu/food/plant/pesticides/eu-pesticides-databa se/public/?event=pesticide.residue.

CurrentMRL\&language $=\mathrm{EN}$
[6] Lin C H, Lerch R N, Thurman E M, et al. Determination of isoxaflutole (balance) and its metabolites in water using solid phase extraction followed by high-performance liquid chromatography with ultraviolet or mass spectrometry [J]. Journal of Agricultural and Food Chemistry, 2002, 50 (2): 5816-5824.

[7] Lin C H, Lerch R N, Thurman E M, et al. Improved HPLC-MS/ MS method for determination of isoxaflutole (balance) and its metabolites in soils and forage plants [J]. Journal of Agricultural and Food Chemistry, 2007, 55 (10): 3805-3815.

[8] Rouchaud J, Neus O, Eelen H, et al. Siol metabolism of isoxaflutole in corn [J]. Archives of Environmental Contamination and Toxicology, 2002, 42 (3): 280-285.

[9] Yang C Z, Wang C S, Cheng Y, et al. Determination of isoxaflutole and its metabolite residues in maize by HPLC-MS/MS [J]. Food Science, 2011, 32 (22): 280-284.

[10] National Health and Family Planning Commission of the People's Republic of China, The Ministry of Agriculture of the People's Republic of China. National food safety standard-Maximum residue limits for pesticides in food [S]. Beijing: Standards Press of China, 2016.

[11] Liu X G, Xu J, Li Y B, et al. Rapid residue analysis of four triazolopyrimidine herbicides in soil, water, and wheat by ultraperformance liquid chromatography coupled to tandem mass spectrometry $[\mathrm{J}]$. Analytical and Bioanalytical Chemistry, 2011, 399 (7): 2539-2547.

[12] Liu N, Dong F S, Xu J et al. Determination of Aminoglycoside Fungicide Validamycin A in Rice Plant by Quick, Easy, Cheap, Effective, Rugged, and Safe Approach Using Ultra High Performance Liquid Chromatography-Electrospray Ionization-Tandem Mass Spectrometry [J]. Food Analytical Methods, (2016) 9: 1736-1744.

[13] Chen X X, Dong F S, Xu J, et al. Enantioseparation and determination of isofenphos-methylenantiomers in wheat, corn, peanut and soil with Supercritical fluidchromatography/tandem mass spectrometric method [J]. Journal of Chromatography B, 1015-1016 (2016) 13-21.

[14] Feng Y Z, Li Y Jin J, et al. Determination of LH-2010A residues in potato and soil [J]. Chinese Journal of Pesticide Science2017, 19 (6): 760-764.

[15] Cao J L, Liu X G, Dong F S et al. Residues and decline dynamics of thifluzamide in rice field [J]. Chinese Journal of Pesticide Science, 2017, 19 (1): 84-92.

[16] He M, Song D, Dong F S, et al. Determination of fipronil and its metabolites in leek and soil by ultrahigh performance liquid chromatography-mass spectrometry [J]. Environmental Chemistry, 2016, 35 (5): 925-932. 